\title{
Upregulation of DR5 and Downregulation of Survivin by IITZ-01, Lysosomotropic Autophagy Inhibitor, Potentiates TRAIL-Mediated Apoptosis in Renal Cancer Cells via Ubiquitin-Proteasome Pathway
}

\author{
Sk Abrar Shahriyar ${ }^{1}$, Seung Un Seo ${ }^{1}$, Kyoung-jin Min ${ }^{2}$, Peter Kubatka ${ }^{3,4}{ }^{(}$, Do Sik Min ${ }^{5}$, \\ Jong-Soo Chang ${ }^{6}$, Dong Eun Kim ${ }^{7}$, Seon Min Woo ${ }^{1, *}$ and Taeg Kyu Kwon ${ }^{1, *(\mathbb{D}}$ \\ 1 Department of Immunology, School of Medicine, Keimyung University, 1095 Dalgubeoldaero, Dalseo-Gu, \\ Daegu 42601, Korea; sksy.kmu@gmail.com (S.A.S.); sbr2010@hanmail.net (S.U.S.) \\ 2 New Drug Development Center, Daegu-Gyeongbuk Medical Innovation Foundation, 80 Chembok-ro, \\ Dong-gu, Daegu 41061, Korea; kjmin@dgmif.re.kr \\ 3 Department of Medical Biology, Jessenius Faculty of Medicine, Comenius University in Bratislava, \\ 03601 Martin, Slovak; kubatkap@gmail.com \\ 4 Department of Experimental Carcinogenesis, Division of Oncology, Biomedical Center Martin, \\ Jessenius Faculty of Medicine, Comenius University in Bratislava, 03601 Martin, Slovak \\ 5 College of Pharmacy, Yonsei University, 85 Songdogwahak-ro, Yeonsu-gu, Incheon 21983, Korea; \\ minds@yonsei.ac.kr \\ 6 Department of Life Science and Chemistry, College of Natural Science Daejin University, Pochon-shi, \\ Kyeinggido 11150, Korea; jchang@daejin.ac.kr \\ 7 Department of Otolaryngology, School of Medicine, Keimyung University, 1095 Dalgubeoldaero, Dalseo-Gu, \\ Daegu 42601, Korea; entkde@dsmc.or.kr \\ * Correspondence: woosm724@gmail.com (S.M.W.); kwontk@dsmc.or.kr (T.K.K.); \\ Tel.: +82-53-258-7358 (T.K.K.)
}

Received: 14 July 2020; Accepted: 20 August 2020; Published: 21 August 2020

\begin{abstract}
Tumor necrosis factor-related apoptosis-inducing ligand (TRAIL) selectively is able to increase apoptosis in cancer cells as agent with minimum toxicity to noncancerous cells. However, all cancer cells are not sensitive to TRAIL-induced apoptosis. In this study, we showed the sub-lethal concentrations of a lysosomotropic autophagy inhibitor, IITZ-01, sensitizes cancer cells (renal, lung, and breast carcinoma) to TRAIL-induced apoptosis through DR5 upregulation and survivin downregulation through ubiquitin-proteasome pathway. Knockdown of DR5 or overexpression of survivin inhibited combined treatment with IITZ-01 and TRAIL-induced apoptosis. IITZ-01 downregulated protein expression of $\mathrm{Cbl}$, ubiquitin E3 ligase, and decreased expression level of $\mathrm{Cbl}$ markedly led to increase DR5 protein expression and TRAIL sensitivity. Moreover, IITZ-01 decreased expression level of survivin protein via downregulation of deubiquitinase ubiquitin-specific protease 9X (USP9X) expression. Taken together, these results provide the first evidence that IITZ-01 enhances TRAIL-mediated apoptosis through DR5 stabilization by downregulation of $\mathrm{Cbl}$ and USP9X-dependent survivin ubiquitination and degradation in renal carcinoma cells.
\end{abstract}

Keywords: IITZ-01; TRAIL; DR5; survivin; USP9X

\section{Introduction}

Lysosomes are acidic organelles within cells that degrade and reuse macromolecules through endocytosis, autophagy and phagocytosis, and are involved in regulation of cellular homeostasis [1,2]. Lysosomotropic agents can selectively diffuse, accumulate into lysosomes, and consequently induce $\mathrm{pH}$ 
alteration, decrease of enzyme activity and inhibition of calcium signaling in lysosome [3]. In addition, several lysosomotropic drugs break down phagocytosis, endocytosis and autophagy by disrupting membrane fusion between intracellular organelles [4-6]. Chloroquine (CQ) and hydroxychloroquine (HCQ), well-known lysosomotropic drugs, increase lysosomal membrane permeabilization by neutralizing intracellular lysosomal $\mathrm{pH}$, resulting in the induction of apoptotic cell death in cancer $[7,8]$. Moreover, two lysosomotropic agents can potentiate anti-cancer effect to various chemotherapeutic drugs and overcome resistance to anti-cancer drugs or irradiation in many cancer cells [9-13]. Therefore, lysosomotropic agents are capable of increasing therapeutic efficacy of tumors, but the underlying molecular mechanism is not clear.

IITZ-01, as benzimidazole analogs of morpholino s-triazine, has been kwon to contain lysosomotrpopic properties and anti-cancer activity [14,15]. IITZ-01 accumulates autophagosome by inhibiting autophagic flux through damaged lysosome. In addition, IITZ-01 decreases mitochondria membrane potential through downregulation of Bcl-2 and IAP family proteins followed by caspase-dependent apoptosis in breast cancer cells [16].

The tumor necrosis factor-related apoptosis-inducing ligand (TRAIL) targets malignant cells by binding to the death receptors (DRs), followed by the increase of caspase-dependent apoptosis except normal cells $[17,18]$. Although TRAIL is considered to be a strong therapeutic agent of malignant cells, many malignant cells have been demonstrated to be resistant to TRAIL. Therefore, many researchers have reported that combined treatment with numerous sensitizing agents is able to overcome TRAIL resistance $[19,20]$.

In our present study, we found the effect of IITZ-01 as a novel TRAIL sensitizer. IITZ-01 induced Cbl-mediated DR5 stabilization and USP9X-dependent survivin degradation, resulted in the enhancement to TRAIL sensitivity in cancer.

\section{Results}

\subsection{IITZ-01 Increases TRAIL Sensitivity in Renal Carcinoma Cells}

IITZ-01 exerts an anticancer effect in breast, colon and prostate cancer cells $[15,16]$. We examined whether IITZ-01 could augment TRAIL-induced apoptosis in human renal carcinoma cells. As shown in Figure 1a, individual IITZ-01 $(0.5,1 \mu \mathrm{M})$ and TRAIL $(30,50 \mathrm{ng} / \mathrm{mL})$ had no effect on apoptosis in human renal carcinoma (Caki-1 and ACHN) cells, but combined treatment of IITZ-01 and TRAIL remarkably increased the sub-G1 population and cleavage of PARP. Furthermore, IITZ-10 plus TRAIL treatment increased Annexin V/7-Aminoactinomycin D (7-AAD) double positive cells (Figure 1b). We observed typical apoptotic morphologies, including blebbing, apoptotic bodies, exemplary chromatin damage in the nuclei and DNA fragmentation in Caki-1 cells treated with IITZ-01 and TRAIL (Figure 1c). We investigated whether caspases activation plays a significant role in cell death by combined treatment with IITZ-01 plus TRAIL. Combined treatment increased the caspase-3 activity (Figure 1d). Furthermore, when we used z-VAD-fmk (z-VAD), a pan-caspase inhibitor, pretreatment of z-VAD completely abolished apoptosis and cleavage of caspase-3 by IITZ-01 plus TRAIL (Figure 1e). These results suggest that IITZ-01 enhances TRAIL-induced apoptosis in human renal carcinoma cells. 
a

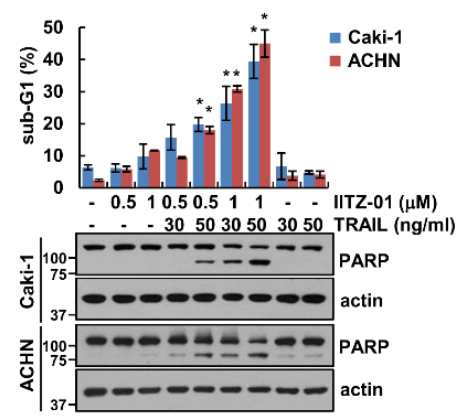

d

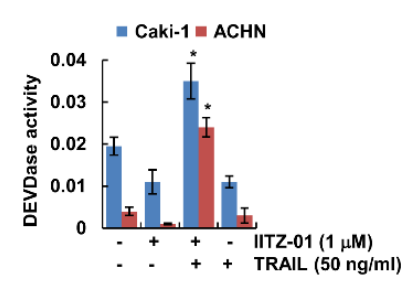

b

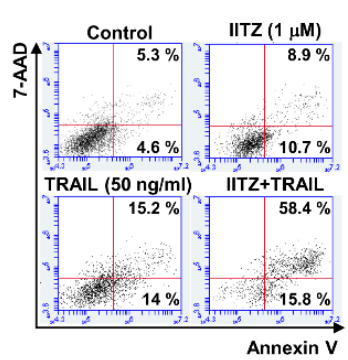

e

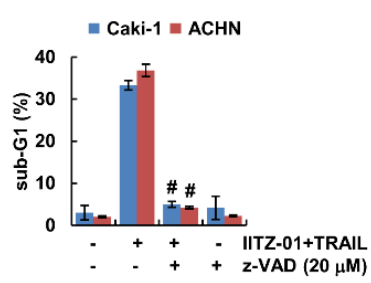

C
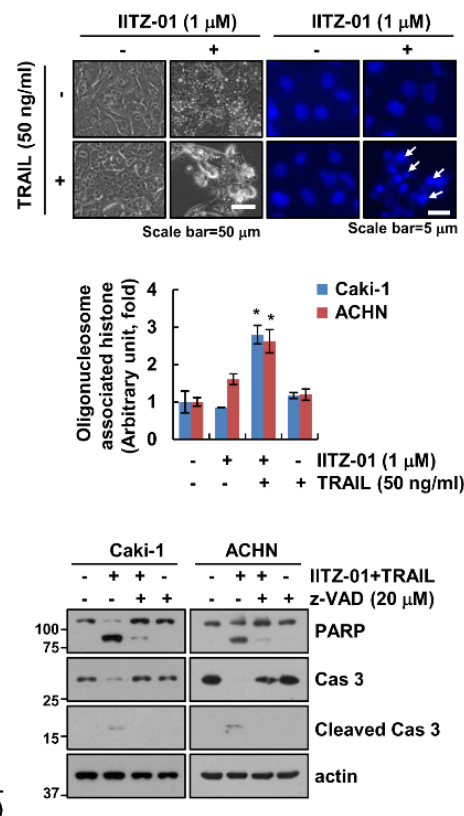

Figure 1. IITZ-01 sensitizes renal carcinoma cells to TNF-related apoptosis-inducing ligand (TRAIL-induced apoptosis. (a) Caki-1 and ACHN cells were incubated with indicated concentrations with IITZ-01 and/or TRAIL for $18 \mathrm{~h}$. The apoptotic population (sub-G1) and protein levels were analyzed by flow cytometry and Western blotting, respectively; (b,c) Caki-1 cells were incubated with $1 \mu \mathrm{M}$ IITZ-01 and/or $50 \mathrm{ng} / \mathrm{mL}$ TRAIL for $18 \mathrm{~h}$. Cell death was detected using Annexin V/7-AAD staining (b). The cell morphology was examined using interference light microscopy. Nuclei condensation and DNA fragmentation were detected using 4', 6' -diamidino-2-phenylindole (DAPI) staining and DNA fragmentation detection kit, respectively (c); (d) Caki-1 and ACHN cells were incubated with $1 \mu \mathrm{M}$ IITZ-01 and/or $50 \mathrm{ng} / \mathrm{mL}$ TRAIL for $18 \mathrm{~h}$. DEVDase (caspase-3) activity was examined using kit as a described in a Material and Methods; (e) Caki-1 and ACHN cells were incubated with $1 \mu \mathrm{M}$ IITZ-01 plus $50 \mathrm{ng} / \mathrm{mL}$ TRAIL in the presence or absence of $20 \mu \mathrm{M} \mathrm{z}$-VAD-fmk (z-VAD). The values in graph $(\mathbf{a}, \mathbf{c}-\mathbf{e})$ represent the mean $\pm \mathrm{SD}$ of three independent experiments. ${ }^{*} p<0.05$ compared to the control. $\# \mathrm{p}<0.05$ compared to IITZ-01 plus TRAIL.

\subsection{Effect of IITZ-01 on Expression Levels of Apoptosis-Related Proteins}

To elucidate the molecular mechanisms leading to apoptosis in IITZ-01 treated Caki- 1 and ACHN cells, we investigated the changes of apoptosis-related proteins expression. IITZ-01 significantly diminished survivin expression and increased DR5 expression, while other apoptosis-related proteins (Mcl-1, XIAP, Bcl-2, Bcl-xL, Bim, cIAP1, cIAP2, DR4, c-FLIP and Bax) were not affected by IITZ-01 treatment (Figure 2). These results indicate that IITZ-01 induces survivin downregulation and DR5 upregulation, resulting in the increase of TRAIL-mediated apoptosis in caspase-dependent manner. 


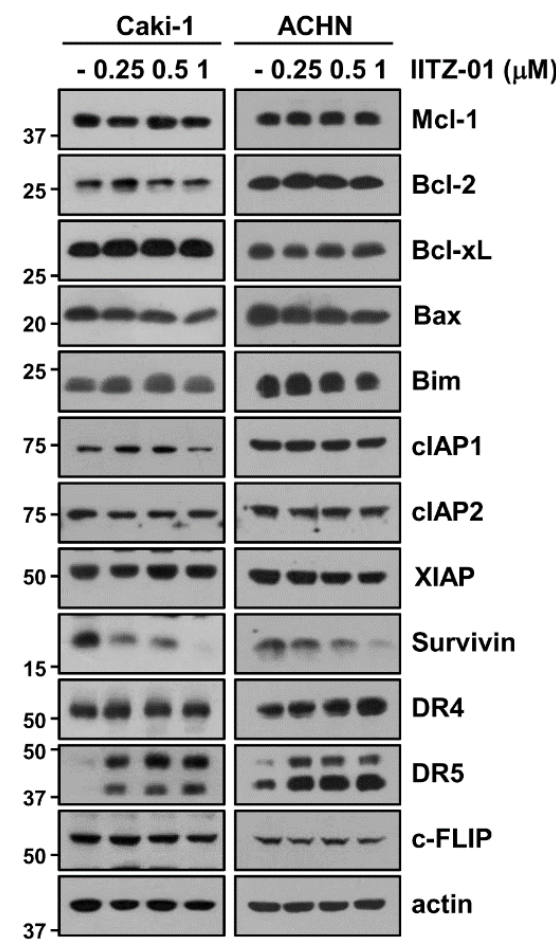

Figure 2. IITZ-01 induces upregulation of DR5 and downregulation of survivin. Caki-1 and ACHN cells were incubated with $0.25-1 \mu \mathrm{M}$ IITZ-01 for $18 \mathrm{~h}$. The protein expression levels of apoptosis related proteins and actin were determined by Western blotting.

\subsection{Upregulation of DR5 by IITZ-01 Is Associated with TRAIL-Induced Apoptosis}

DR5 plays a major role in TRAIL-mediated apoptosis [21,22], and other lysosomotropic agents induce DR5 upregulation resulting in the enhancement of TRAIL sensitivity [23]. Expectably, DR5 protein level was increased by IITZ-01 after $3 \mathrm{~h}$ (Figure 3a). To explore the IITZ-01-mediated DR5 upregulation at the transcriptional levels, we checked DR5 mRNA level and promoter activity. However, IITZ-01 did not alter DR5 mRNA level and promoter activity (Figure 3b,c). Next, we investigated the impact of IITZ-01 on DR5 protein stability using the cycloheximide (CHX). Combined treatment with CHX and IITZ-01 more maintained DR5 protein level compared to CHX alone (Figure 3d). Next, we investigated the importance of the DR5 upregulation in IITZ-01 plus TRAIL-induced apoptosis, Caki- 1 and ACHN cells were transiently transfected with DR5 siRNA. Knockdown of DR5 significantly reduced apoptosis by the combined treatment of IITZ-01 and TRAIL (Figure 3e). Therefore, these data indicate that upregulation of DR5 expression is involved in IITZ-01 plus TRAIL-induced apoptosis. 
a

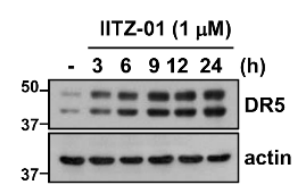

d

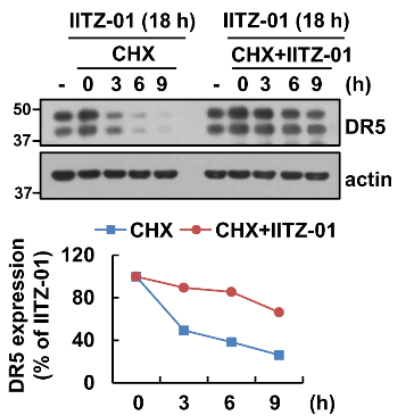

b

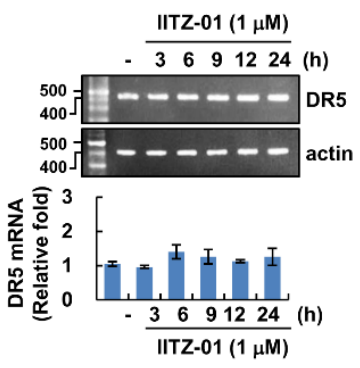

e

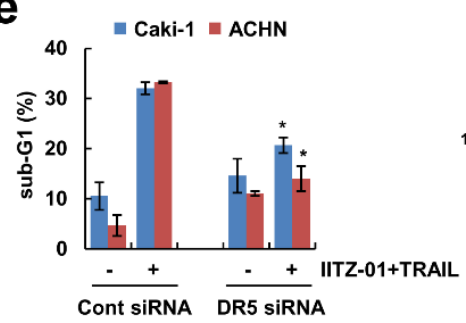

C

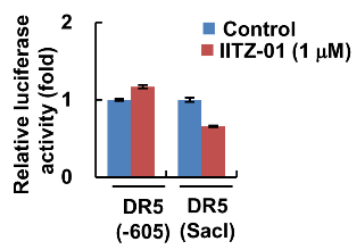

Figure 3. DR5 stabilization contributes to the sensitization effect of IITZ-01 on TRAIL-induced apoptosis in Caki-1 cells. (a,b) Caki-1 cells were incubated with $1 \mu \mathrm{M}$ IITZ-01 for indicated time periods. The protein and mRNA levels were determined by Western blotting (a) and RT-PCR (upper panel)/qPCR (low pane), respectively (b); (c) Caki-1 cells were transiently transfected with DR5(-605) or DR5(SacI) promoter and incubated with $1 \mu \mathrm{M}$ IITZ-01 for $18 \mathrm{~h}$. The cells were lysed and the luciferase activity was measured as a described in a Material and Methods; (d) Caki-1 cells were incubated with $1 \mu \mathrm{M}$ IITZ-01 for $18 \mathrm{~h}$, washed with PBS, and then treated with $20 \mu \mathrm{g} / \mathrm{mL}$ cycloheximide (CHX) and/or $1 \mu \mathrm{M}$ IITZ-01 for the indicated time periods. The band intensity of the DR5 protein was measured using ImageJ; (e) Caki-1 and ACHN cells were transiently transfected with control (Cont) siRNA or DR5 siRNA, and then incubated with $1 \mu \mathrm{M}$ IITZ-01 and $50 \mathrm{ng} / \mathrm{mL}$ TRAIL for $18 \mathrm{~h}$. The apoptotic population (sub-G1) and protein levels were analyzed by flow cytometry (e) and Western blot (d,e). The values in graph $(\mathbf{b}, \mathbf{c}, \mathbf{e})$ represent the mean $\pm \mathrm{SD}$ of three independent experiments. ${ }^{*} p<0.05$ compared to the IITZ-01 plus TRAIL in control siRNA.

\subsection{Downregulation of Cbl Plays a Critical Role in DR5 Upregulation and TRAIL Sensitivity by IITZ-01}

Previous studies reported that E3 ligase $\mathrm{Cbl}$ contributes to DR5 ubiquitination and degradation [24,25]. We also reported that CQ-mediated Cbl downregulation induce decrease of DR5 protein expression level [23]. Following these, we checked the role of Cbl in DR5 expression in IITZ-01 treated cells. IITZ-01 downregulated $\mathrm{Cbl}$ protein level in a time-dependent manner, but not mRNA level (Figure 4a). We further examined whether IITZ-01 can regulate Cbl stabilization. As shown in Figure 4b, IITZ-01 significantly inhibited Cbl stability compared with CHX alone. To further confirm the involvement of $\mathrm{Cbl}$ on DR5 upregulation by IITZ-01, we transiently overexpressed Cbl. Overexpression of Cbl markedly diminished IITZ-01 induced DR5 upregulation (Figure 4c). Downregulation of Cbl by siRNA induced TRAIL-mediated apoptosis, cleavage of PARP and DR5 upregulation in Caki-1 and ACHN cells (Figure $4 \mathrm{~d}$ ). These data demonstrate that $\mathrm{Cbl}$ is important role in stability of DR5 and sensitization of TRAIL by IITZ-01. 
a

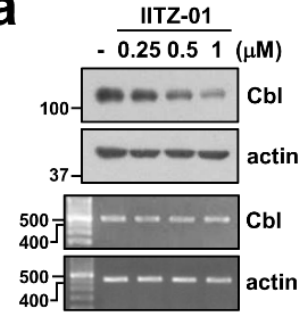

C

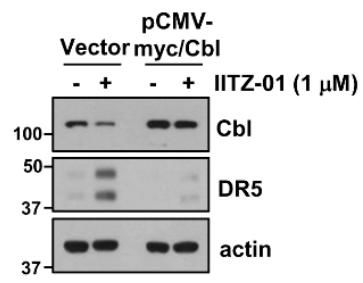

b
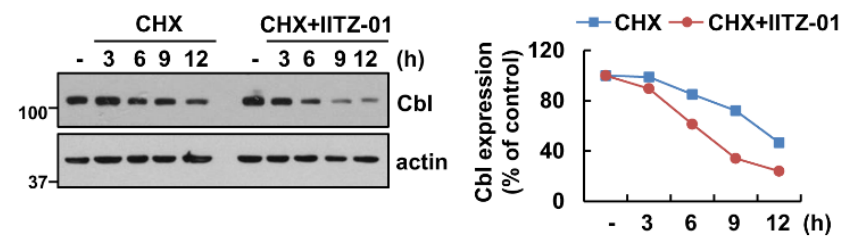

d

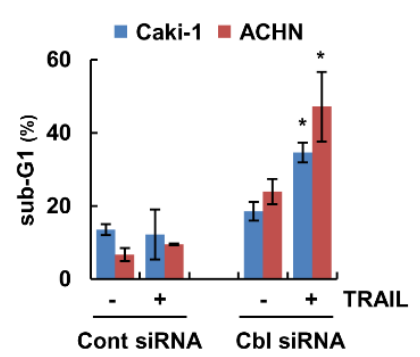

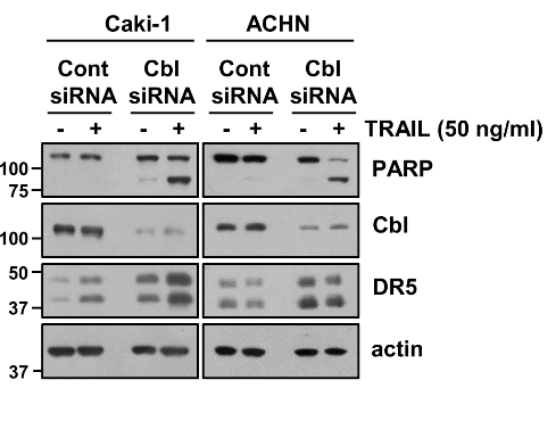

Figure 4. Downregulation of $\mathrm{Cbl}$ is involved in IITZ-01-mediated DR5 upregulation and TRAIL sensitization. (a) Caki-1 cells were incubated with $0.25-1 \mu \mathrm{M}$ IITZ-01 for $18 \mathrm{~h}$. The protein and mRNA levels were determined by Western blotting and RT-PCR, respectively; (b) Caki- 1 cells were incubated with $20 \mu \mathrm{g} / \mathrm{mL}$ CHX and/or $1 \mu \mathrm{M}$ IITZ- 01 for the indicated time periods. The band intensity of the $\mathrm{Cbl}$ protein was measured using Image J; (c) Caki-1 cells were transfected with pCMV-myc (Vector) or pCMV-myc/Cbl and treated with $1 \mu \mathrm{M}$ IITZ-01 for $18 \mathrm{~h}$; (d) Caki-1 and ACHN cells were transiently transfected with Cont siRNA or Cbl siRNA, and then incubated with $50 \mathrm{ng} / \mathrm{mL}$ TRAIL for $18 \mathrm{~h}$. The apoptotic population (sub-G1) and protein levels were analyzed by flow cytometry (d) and Western blotting $(\mathbf{b}-\mathbf{d})$, respectively. The values in graph (d) represent the mean $\pm \mathrm{SD}$ of three independent experiments. ${ }^{*} p<0.05$ compared to the TRAIL in control siRNA.

\subsection{Survivin Degradation Is Important for IITZ-01 Plus TRAIL-Induced Apoptosis}

We next investigated whether IITZ-01 modulates survivin expression at the transcriptional level. Survivin mRNA expression was not altered by IITZ-01 treatment (Figure 5a). Therefore, we investigated whether IITZ-01 reduces survivin expression at the post-translational level. Combined treatment with IITZ-01 and CHX more quickly decreased survivin protein expression rather than CHX alone (Figure 5b). In addition, MG132, a proteasome inhibitor, reversed IITZ-01-induced survivin downregulation (Figure 5c). To investigate the functional role of survivin in combined treatment IITZ-01 plus TRAIL-mediated apoptosis, we used survivin-overexpressed Caki-1 and ACHN cells. Ectopic expression of survivin prevented sub-G1 population and PARP cleavage by combined treatment (Figure 5d). Therefore, these data suggested that IITZ-01 reduces survivin expression via proteasome activity at the posttranslational level, and downregulation of survivin contributes to IITZ-01-induced TRAIL sensitization. 
a

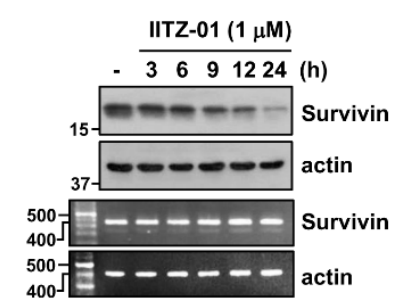

b

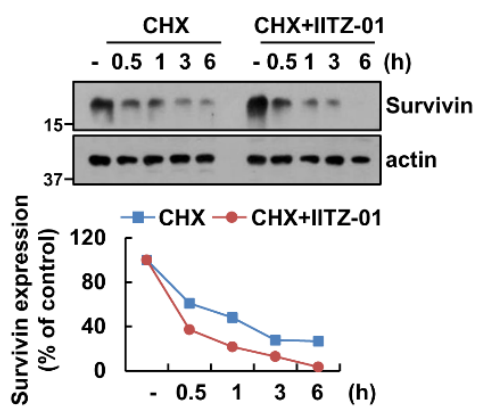

C

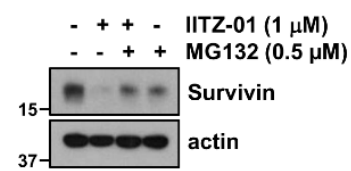

d
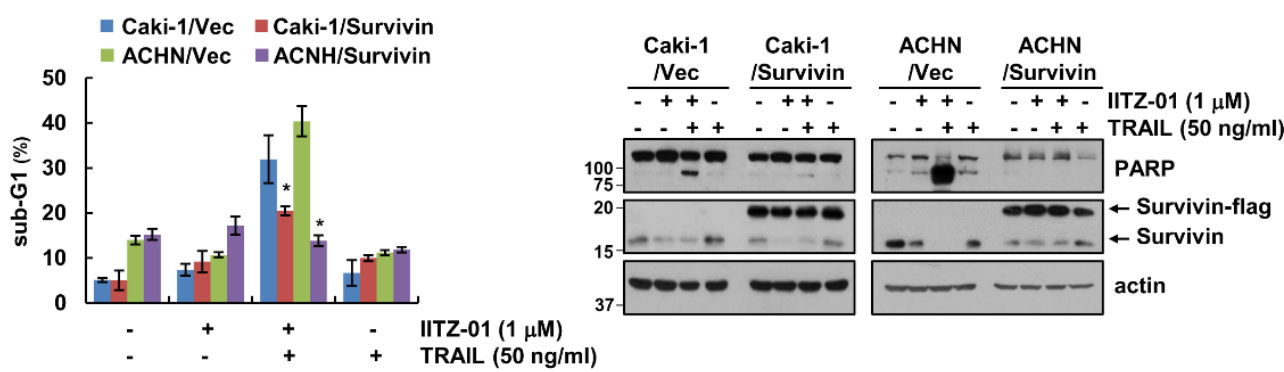

Figure 5. Survivin downregulation contributes to the sensitization effect of IITZ-01 on TRAIL-induced apoptosis in Caki-1 cells. (a) Caki-1 cells were incubated with $1 \mu \mathrm{M}$ IITZ-01 for indicated time periods. The protein and mRNA levels were determined by Western blotting or RT-PCR, respectively; (b) Caki-1 cells were incubated with $20 \mu \mathrm{g} / \mathrm{mL} \mathrm{CHX}$ and/or $1 \mu \mathrm{M}$ IITZ-01 for the indicated time periods. The band intensity of the survivin protein was measured using Image J; (c) Caki-1 cells were pretreated with $0.5 \mu \mathrm{M}$ MG132, and then incubated with $1 \mu \mathrm{M}$ IITZ-01 for $18 \mathrm{~h}$; (d) Vector-transfected cells (Caki-1/Vec and $\mathrm{ACHN} / \mathrm{Vec}$ ) and survivin-overexpressing cells (Caki-1/Survivin and ACHN/Survivin) were incubated with $1 \mu \mathrm{M}$ IITZ-01 and/or $50 \mathrm{ng} / \mathrm{mL}$ TRAIL for $18 \mathrm{~h}$. The values in graph $(\mathbf{b}, \mathbf{d})$ represent the mean $\pm \mathrm{SD}$ of three independent experiments. ${ }^{*} p<0.05$ compared to the IITZ-01 plus TRAIL in Vector cells.

\subsection{USP9X-Dependent Survivin Degradation Is Important for IITZ-01 Plus TRAIL-Induced Apoptosis}

Among deubiquitinases, ubiquitin specific peptidase 9X (USP9X) and STAM-binding protein-like 1 (STAMBPL1) are involved in stabilization of survivin [26,27]. Therefore, we examined protein expression levels of USP9X and STAMBPL1 by IITZ-01. As shown in Figure 6a, IITZ-01 decreased USP9X protein expression, but not STAMBPL1. Moreover, USP9X mRNA expression was not changed by IITZ-01 (Figure 6b). Therefore, we examined post-translational regulation of IITZ-01-mediated UPS9X downregulation and found CHX plus IITZ-01 more degraded USP9X expression (Figure 6c). To examine whether USP9X physically interacts with survivin, we performed an immunoprecipitation assay by using Caki-1 cells. Immunoprecipitation assay revealed that USP9X reciprocally binds to survivin, but not control IgG (Figure 6d). To verify the functional role of USP9X in degradation of survivin by IITZ-01, we used constructs with wild-type (WT) and catalytically inactive mutant (C1566S) of USP9X. USP9X WT markedly impeded survivin degradation by IITZ-01 in Caki-1/Vector cells, whereas USP9X/C1566S still revealed IITZ-01-inhibited survivin expression (Figure 6e). Next, we examined whether USP9X regulates survivin deubiquitination in cells. Transfection of cells with $\mathrm{HA}-\mathrm{Ub}$ expressing vector induced survivin ubiquitination (Figure 6f). However, ubiquitination of survivin was significantly decreased in USP9X WT-overexpressed cells. In contrast, catalytically inactive mutant USP9X increased survivin ubiquitination (Figure 6f). Taken together, our results suggest that IITZ-01 can inhibit survivin ubiquitination via downregulation of USP9X, resulted in degradation of survivin protein expression. 
a

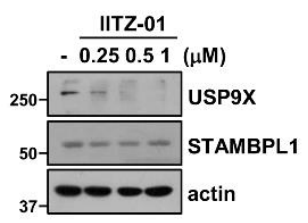

d

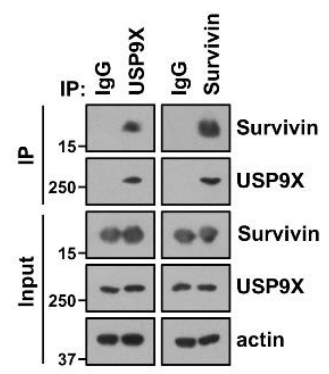

b

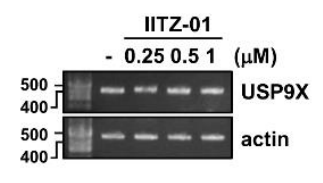

e

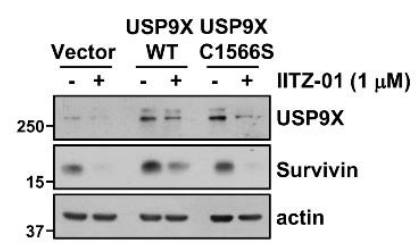

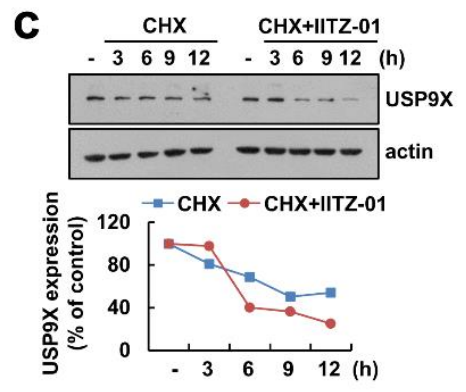

f

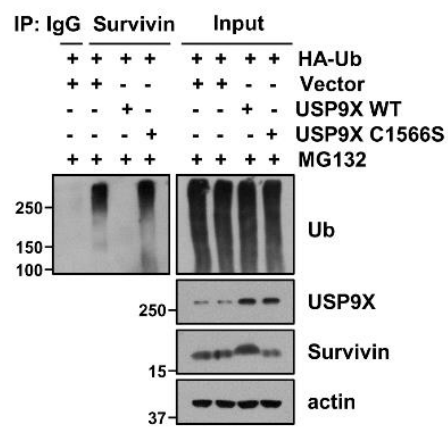

Figure 6. Degradation of survivin is critical to induction of IITZ-01 plus TRAIL-induced apoptosis through downregulation of USP9X. (a,b) Caki-1 cells were incubated with $0.25-1 \mu \mathrm{M}$ IITZ-01 for $18 \mathrm{~h}$. USP9X mRNA levels were determined by RT-PCR; (c) Caki-1 cells were incubated with $20 \mu \mathrm{g} / \mathrm{mL} \mathrm{CHX}$ and/or $1 \mu \mathrm{M}$ IITZ-01 for the indicated time periods. The band intensity of the USP9X protein was measured using Image J; (d) The interaction with survivin and USP9X was indicated by immunoprecipitation (IP) assay; (e) Caki-1 cells were transiently transfected with pDESTS1 (Vector), pDESTS1-USP9X (USP9X WT) or pDESTS1-USP9X/C1566S (USP9X C1566S), and then incubated with $1 \mu \mathrm{M}$ IITZ-01 for $18 \mathrm{~h}$; (f) To analyze the ubiquitination of endogenous survivin, Caki-1 cells were transfected with HA-ubiquitin (HA-Ub), USP9X WT and USP9X C1566S and treated with $0.5 \mu \mathrm{M} \mathrm{MG132.}$ Cells were lysed in 1\% sodium dodecyl sulfate (SDS) buffer to disrupt interacting proteins and cell lysates were then diluted to $0.1 \%$ SDS, followed by the immunoprecipitation using an anti-survivin. Survivin ubiquitination was detected by Western blotting using an horseradish peroxidase (HRP)-conjugated anti-Ub antibody. The protein levels were analyzed by Western blotting $(\mathbf{a}, \mathbf{c}-\mathbf{f})$.

\subsection{IITZ-01 Plus TRAIL Treatment Effects on Apoptosis in Various Cancerous but Not in Normal Cells}

We further investigate whether IITZ-01 plus TRAIL trigger apoptosis in other carcinoma cells and normal cells. As shown in Figure 7a, combined treatment with IITZ-01 and TRAIL augmented sub-G1 population and PARP cleavage in other renal cancer cells (A498), human lung cancer cells (A549) and breast cancer cells (MCF7). Moreover, IITZ-01 upregulated DR5 and downregulated Cbl, USP9X and survivin in all examined cancer cells (Figure 7b). However, IITZ-01 plus TRAIL treatment had no effect on morphological apoptotic bodies and sub-G1 populations in normal human mesangial cells (MC) and normal human skin fibroblast (HSF) cells (Figure 7c). In addition, we did not distinguish survivin protein level in normal cells (Figure 7d). We also analyzed survivin and DR5 expression in renal clear cell carcinoma patient using TCGA databases through University of California Santa Cruz (UCSC) Xena Public Data Hub (xena.ucsc.edu) [28]. Survivin and DR5 is highly expressed in tumor (Figure S1a). Moreover, high expression of survivin and DR5 is shorter the survival rate and showed poor prognosis (Figure S1b). Therefore, these data indicate that IITZ-01 sensitizes to TRAIL-induced cell death in cancer cells. 
a
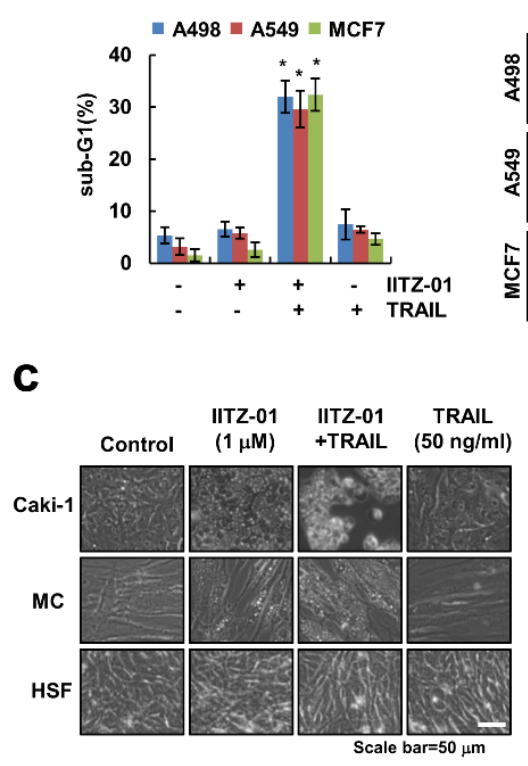
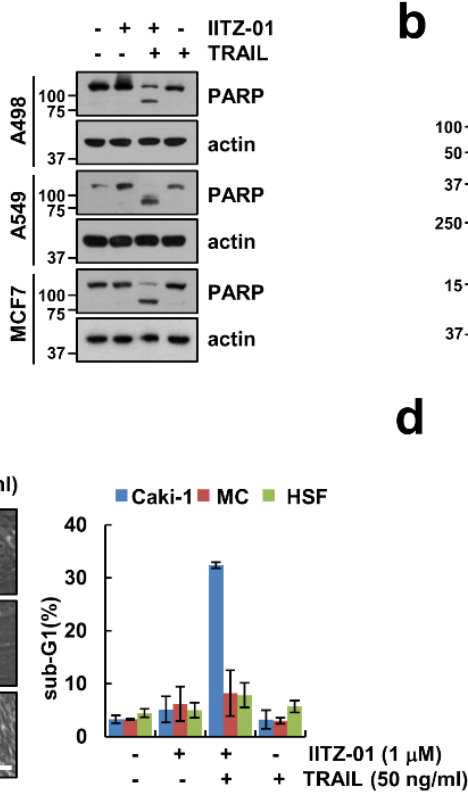

b
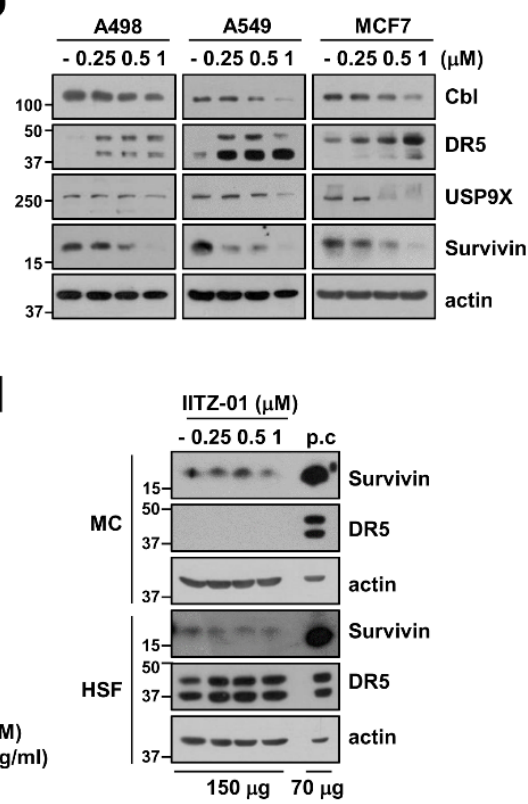

Figure 7. IITZ-01 plus TRAIL induces apoptosis on other carcinoma cells, but not normal cells. (a) Renal carcinoma (A498), lung carcinoma (A549) and breast carcinoma (MCF7) were incubated with $1 \mu \mathrm{M}$ IITZ-01 and/or $50 \mathrm{ng} / \mathrm{mL}$ TRAIL for $18 \mathrm{~h}$; (b) A498, A549 and MCF7 cells were incubated with 0.25-1 $\mu \mathrm{M}$ IITZ-01 for 18 h; (c) Caki-1, human renal normal mesangial cells (MC) and human skin fibroblast (HSF) cells were incubated with $1 \mu \mathrm{M}$ IITZ-01 and/or $50 \mathrm{ng} / \mathrm{mL}$ TRAIL for $18 \mathrm{~h}$. The cell morphology was examined using interference light microscopy; (d) MC and HSF cells were incubated with $0.25-1 \mu \mathrm{M}$ IITZ-01 for $18 \mathrm{~h}$. (positive control (p.c); Caki-1 cell lysate). The apoptotic population (sub-G1) and protein levels were analyzed by flow cytometry $(\mathbf{a}, \mathbf{c})$ and Western blotting $(\mathbf{a}, \mathbf{b}, \mathbf{d})$, respectively. The values in graph $(\mathbf{a}, \mathbf{c})$ represent the mean $\pm \mathrm{SD}$ of three independent experiments. ${ }^{*} p$ $<0.05$ compared to the control.

\section{Discussion}

In this study, we demonstrated that lysosomotropic autophagy inhibitor, IITZ-01, enhanced TRAIL-mediated apoptosis in cancer cells, but not in normal cells. We found that stabilization of DR5 and degradation of survivin by IITZ-01 play a critical role in TRAIL-mediated apoptosis. Downregulation of $\mathrm{Cbl}$ E3 ligase is associated with DR5 upregulation in IITZ-01 treated cells. In addition, IITZ-01 decreased survivin stability via downregulation of USP9X expression. Therefore, we suggested that IITZ-01 could enhance TRAIL-induced apoptosis via modulation of DR5 and survivin expression (Figure 8).

IITZ-01, a novel potent lysosomotropic autophagy inhibitor, induced vacuolated appearance of cells due to deacidify lysosomes. IITZ-01 showed more than 10-fold potent autophagy inhibition compare with chloroquine [16]. As shown in Figure 1b, IITZ-01 also induced vacuolation in renal carcinoma Caki-1 cells. Previous study reported about the mechanism of IITZ-01 decreases IAP family protein involving cIAP1, XIAP and survivin in triple-negative breast cancer cells [16]. However, in our study, survivin was downregulated by IITZ-01, whereas expression of other IAP family protein (cIAP1, cIAP2 and XIAP) was not changed (Figure 2). This contradiction is believed to be due to the difference between the cell line used and the concentration of the IITZ-01.

DRs expression is critical for TRAIL-mediated apoptosis [29]. IITZ-01 increased DR5 protein level not DR4 (Figure 2). We reported the anti-cancer effect of lysosomotropic compounds (CQ, Monensin, and Nigericin) in renal carcinoma Caki-1 cells [23]. Other lysosomotropic compounds also increased DR5 expression. CQ $(30 \mu \mathrm{M})$ induced both mRNA and protein of DR5 expression, while monensin, and nigericin only increased stability of DR5 protein. Interestingly, all drugs decreased Cbl expression. 
Although $\mathrm{Cbl}$ induces proteasome-dependent degradation via ubiquitination of target proteins, $\mathrm{Cbl}$ also could modulate lysosomal degradation of target proteins in a ubiquitin-dependent or -independent manner. For examples, $\mathrm{Cbl}$ mediates lysosomal degradation of K63-linked polyubiquitinating gp130 in interleukin 6-treated cells, and mono-ubiquitinating Notch1 in skeletal myoblast [30]. $\mathrm{Cbl}$ regulates lysosomal degradation of cystic fibrosis transmembrane conductance regulator in an ubiquitin-independent manner [31]. Furthermore, $\mathrm{Cbl}$ negatively regulates receptor-mediated signaling activation via lysosome-dependent degradation. After ligand engagement, internalized $\mathrm{T}$ cell receptor (TCR) is degraded by $\mathrm{Cbl}$ in lysosomes [32], and ligand binding EphB1 receptor is also Cbl-dependently degraded in lysosome [33]. In addition, $\mathrm{Cbl}$ negatively modulates activation of protein tyrosine kinase through the lysosomal pathway $[26,27]$. Although proteasome inhibitors upregulate DR5 expression [34], lysosome is also important for modulation of DR5 proteins expression [35]. In our study, since IITZ-01 induced DR5 expression in a Cbl-dependent manner (Figure 4c) and IITZ-01 is a lysosomotropic agent, it is a possibility that IITZ-01 inhibits lysosomal degradation of DR5.

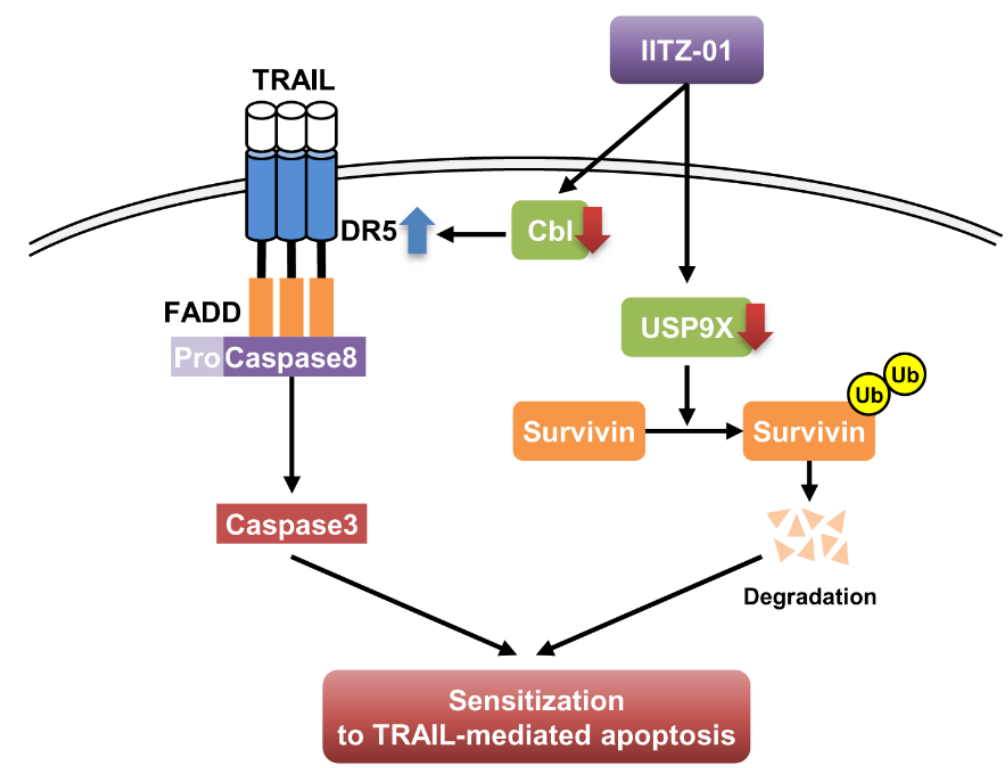

Figure 8. The diagram indicating the mechanism of IITZ-01-induced TRAIL sensitization.

Survivin contains only a single BIR domain and is one of the inhibitor of apoptosis (IAP) family proteins. Upregulation of survivin protein inhibit apoptosis both in a caspase-dependent and -independent way by interacting with XIAP and mitochondrial apoptosis-inducing factor (AIF), respectively [36,37]. Therefore, downregulation of survivin protein expression is targeted to induce cancer cell death. Here, we identified that IITZ-01 induced survivin expression via protein stabilization (Figure 5a,b). Degradation of survivin is mainly mediated by proteasome via ubiquitination [38]. E3 ligase XIAP regulates the degradation of survivin by ubiquitin-proteasome pathway [39]. However, IITZ-01 did not affect on expression levels of XIAP (Figure 2). Deubiquitinating enzymes (DUBs) can prevent protein degradation by removing ubiquitin from target substrate [40]. Previously, Chen et al. reported that USP9X is involved in deubiquitination and degradation of survivin by inhibition of long noncoding RNA LNC473 [41]. Furthermore, we reported that STAM-binding protein-like 1 (STAMBPL1) directly interacts and deubiquitinates survivin expression [42]. However, IITZ-01 only decreased USP9X expression and ectopic expression of USP9X prevented downregulation of survivin in IITZ-01 treated cells (Figure 6a,c). However, it need to further studies to identify the molecular mechanism of IITZ-01-induced downregulation of USP9X. Moreover, we found IITZ-01 downregulated USP9X through post-translation level (Figure $6 b, c$ ). 
Taken all together, we suggest that ubiquitin-proteasome pathway-mediated DR5 upregulation and survivin downregulation have a critical role in lysosomotropic autophagy inhibitor (IITZ-01)-mediated sensitization of cancer cells to TRAIL-induced apoptosis.

\section{Materials and Methods}

\subsection{Cell Cultures and Materials}

Human renal carcinoma (Caki-1, ACHN and A498), human lung cancer (A549) and human breast cancer (MCF7) were procured from American Type Culture Collection (Manassas, VA, USA). Lonza (Basel, Switzerland) provided human mesangial cells, and Korea Cell Line Bank (Seoul, Korea) provided normal human skin fibroblasts cells. These cells were cultured in appropriate medium containing $10 \%$ fetal bovine serum, $1 \%$ penicillin/streptomycin and $100 \mu \mathrm{g} / \mathrm{mL}$ gentamicin at $37^{\circ} \mathrm{C}$ in a humidified atmosphere with $5 \% \mathrm{CO}_{2}$. IITZ-01 was purchased from Selleckchem (Houston, TX, USA). Human recombinant TRAIL and zVAD-fmk were provided by R\&D system (Minneapolis, MN, USA). MG132 and lactacystin were supplied from Calbiochem (San Diego, CA, USA) and Enzo Life Sciences (Ann Arbor, MI, USA), respectively. Cycloheximide was provided from Sigma Chemical Co. (St. Louis, MO, USA). The primary antibodies were obtained as follows: anti-PARP, anti-cleaved caspase-3, anti-Bcl-xL, anti-DR5 from Cell Signaling Technology (Beverly, MA, USA). Anti-Bim, anti-Bax and anti-XIAP from BD Biosciences (San Jose, CA, USA). Anti-Mcl-1, anti-Bcl-2, anti-cIAP2, anti-Cbl from Santa Cruz Biotechnology (St. Louis, MO, USA). Anti-survivin from R\&D system (Minneapolis, MN, USA). Anti-cIAP1 and anti-DR4 from Abcam (Cambridge, MA, USA), Anti-USP9X from Abnova (Taipei City, Taiwan). Anti-caspase-3 and anti-c-FLIP from Enzo Life Sciences (San Diego, CA, USA). Anti-actin from Sigma Chemical Co. (St. Louis, MO, USA). pCMV-Myc-Cbl plasmid was a gift from Dr. S. J. Kim (CHA University, Korea), and USP9X wild-type and USP9X/C1566S plasmids were a gift from Dr. D. S. Lim (KAIST, Korea).

\subsection{Flow Cytometry Analysis}

To analyze apoptosis, cells were harvested and fixed with $95 \%$ ethanol at least $1 \mathrm{~h}$ at $4{ }^{\circ} \mathrm{C}$. Furthermore, cells were incubated in $1.12 \%$ sodium citrate buffer containing RNase at $37{ }^{\circ} \mathrm{C}$ for $30 \mathrm{~min}$, added to $50 \mu \mathrm{g} / \mathrm{mL}$ propidium iodide, and analyzed using BD Accuri ${ }^{\mathrm{TM}} \mathrm{C} 6$ flow cytometer (BD Biosciences, San Jose, CA, USA) [43].

\subsection{Western Blotting}

Cells have been lysed in RIPA lysis buffer (20 mM HEPES and 0.5\% Triton X-100, pH 7.6) and supernatant fraction were collected. Proteins were separated by Sodium Dodecyl Sulfate-Polyacrylamide Gel Electrophoresis (SDS-PAGE) and transferred to the nitrocellulose membranes (GE Healthcare Life Science, Pittsburgh, PO, USA). Incubated with specific antibody and bands were detected using Immobilon Western Chemiluminescent horseradish peroxidase (HRP) Substrate (EMD Millipore, Darmstadt, Germany).

\subsection{Annexin $V$ and 7-AAD Staining}

FITC-conjugated Annexin V and 7-aminoactinomycin D (7-AAD) (BD Pharmingen, San Jose, CA, USA) were used to estimate cell death mode. Cells were washed in cold PBS and resuspended in Annexin V-binding buffer. We added Annexin V-FITC and 7-AAD into the suspended cells, and then incubated for $15 \mathrm{~min}$ at room temperature in the dark. The cell death population was detected by flu BD Accuri ${ }^{\mathrm{TM}}$ C6 flow cytometer (BD Biosciences, San Jose, CA, USA).

\subsection{DAPI, DNA Fragmentation Assay and Caspase Activity Assay}

To investigate the nuclei condensation, cellular nuclei cells were stained with $300 \mathrm{nM} \mathrm{4}{ }^{\prime}$, 6'-diamidino-2-phenylindole solution (Roche, Mannheim, Germany), and we viewed fluorescence 
images using fluorescence microscopy (Carl Zeiss, Jena, Germany) [44]. To analyze DNA fragmentation, we used death detection ELISA plus kit (Boehringer Mannheim, Indianapolis, IN, USA) according to the manufacturer's recommendations. To measure DEVDase activity, cells were treated with IITZ-01 and/or TRAIL, harvested, and incubated with reaction buffer containing acetyl-Asp-Glu-Val-Asp p-nitroanilide (Ac-DEVD-pNA) substrate, as previously mentioned [45].

\subsection{Reverse Transcription-Polymerase Chain Reaction (RT-PCR) and Quantitative PCR ( $q P C R$ )}

To isolate the total RNA, we used TriZol reagent (Life Technologies, Gaithersburg, MD, USA), and obtained cDNA using M-MLV reverse transcriptase (Gibco-BRL, Gaithersburg, MD, USA). For PCR, we used Blend Taq DNA polymerase (Toyobo, Osaka, Japan) with primers targeting DR5, Cbl, survivin and actin as mentioned in our previous studies $[46,47]$. For qPCR we utilize SYBR Fast qPCR Mix (Takara Bio Inc., Shiga, Japan) and reactions were performed on Thermal Cycler Dice ${ }^{\circledR}$ Real Time System III (Takara Bio Inc., Shiga, Japan). The following primers were used for the amplification of DR5 and actin as described as our previous study [23]. We used actin as a reference Gene to calculate the threshold cycle number $(\mathrm{Ct})$ of DR5 gene and reported the delta-delta $\mathrm{Ct}$ values of the genes.

\subsection{Luciferase Activity Assay}

The DR5 (-605) or DR5 (SacI) promoter-constructs transfected into the cells using Lipofectamine ${ }^{\mathrm{TM}} 2000$ (Invitrogen, Carlsbad, CA, USA). Furthermore, cells were collected and harvested in lysis buffer ( $25 \mathrm{mM}$ Tris-phosphate $\mathrm{pH}$ 7.8, $2 \mathrm{mM}$ EDTA, 1\% Triton X-100, and 10\% glycerol). The supernatants were used to measure the luciferase activity according to the manufacturer's instructions (Promega, Madison, WI, USA).

\subsection{Transfection}

For developing stable cell lines, Caki-1 cells were transfected with the control plasmid pcDNA 3.1(+) vector or pcDNA 3.1(+)/survivin-flag plasmids using Lipofectamine ${ }^{\mathrm{TM}} 2000$ (Invitrogen, Carlsbad, CA, USA). After $24 \mathrm{~h}$, cells were picked by $700 \mu \mathrm{g} / \mathrm{mL}$ G418 (Invitrogen, Carlsbad, CA, USA). For knockdown of gene, Caki-1 cells were transfected with the control siRNA (Bioneer, Daejeon, Korea), DR5 siRNA (Invitrogen, Carlsbad, CA, USA) or Cbl siRNA (Santa Cruz Biotechnology, St. Louis, MO, USA) using Lipofectamine ${ }^{\circledR}$ RNAiMAX Reagent (Invitrogen, Carlsbad, CA, USA). Furthermore, protein expressions were checked by western blotting.

\subsection{Immunoprecipitation Assay}

Cells were collected, washed with PBS, lysed with RIPA lysis buffer containing $10 \mathrm{mM}$ nethylmaleimide (NEM) (EMD Millipore, Darmstadt, Germany) and $1 \mathrm{mM} \mathrm{PMSF}$, and then sonicated for protein extraction in ice. After sonication, cell lysates were centrifuged at $13,000 \times g$ for $15 \mathrm{~min}$ at $4{ }^{\circ} \mathrm{C}$. The supernatants were incubated with $1 \mu \mathrm{g}$ of anti-USP9X or anti-survivin antibody overnight at $4{ }^{\circ} \mathrm{C}$, and then attached to $20 \mu \mathrm{L}$ of Protein $\mathrm{G}$ agarose bead using the rotator at $4{ }^{\circ} \mathrm{C}$ for $2 \mathrm{~h}$. Cell lysates were washed with RIPA lysis buffer containing $10 \mathrm{mM}$ NEM and $1 \mathrm{mM} \mathrm{PMSF}$, and boiled in $2 \times$ sample buffer for $10 \mathrm{~min}$. Protein-protein interactions were checked by Western blotting.

\subsection{Ubiquitination Assay}

The assay was performed as described in our previous study [45]. Cells were co-transfected with HA-tagged ubiquitin (HA-Ub), USP9X/wild type and UPS9X/C1566S plasmid, and treated with MG132 for $12 \mathrm{~h}$. Immunoprecipitation was performed using the anti-survivin, and ubiquitination of endogenous survivin was checked using HRP-conjugated anti-Ub under denaturing conditions. 


\subsection{Statistical Analysis}

The data were analyzed using a one-way ANOVA and post-hoc comparisons (Student-Newman-Keuls) using the Statistical Package for Social Sciences 22.0 software (SPSS Inc.; Chicago, IL, USA).

\section{Conclusions}

Our study suggests that IITZ-01, a lysosomotropic agent, sensitizes TRAIL-induced apoptosis via DR5 upregulation and survivin downregulation in cancer cells, but not normal cells. In mechanisms, IITZ-01 induces DR5 stabilization by downregulation of Cbl and USP9X-dependent survivin ubiquitination and degradation.

Supplementary Materials: The following are available online at http:/www.mdpi.com/2072-6694/12/9/2363/s1, Figure S1: Analysis of expression and prognostic significance of survivin (BIRC5), DR5 (TNFRSF10B), USP9X and $\mathrm{Cbl}$ in renal clear cell carcinoma. Results were generated using the UCSC Xena browser based on data in TCGA. Figure S2. Uncropped western blots for Figure 1. Figure S3 Uncropped western blots for Figure 2. Figure S4. Uncropped western blots for Figure 3. Figure S5. Uncropped western blots for Figure 4. Figure S6. Uncropped western blots for Figure 5. Figure S7. Uncropped western blots for Figure 6. Figure S8. Uncropped western blots for Figure 7.

Author Contributions: Conceptualization, T.K.K., K.-j.M. and S.M.W.; investigation, S.A.S. and S.U.S.; data curation, P.K., D.S.M., J.S.C. and D.E.K.; writing—original draft preparation, T.K.K., S.M.W. and S.A.S.; supervision, T.K.K.; funding acquisition, T.K.K. All authors have read and agreed to the published version of the manuscript.

Funding: This work was supported by an NRF grant funded by the Korea Government (MSIP) (2014R1A5A2010008, NRF-2018R1D1A3B07049596 and NRF-2019R1A2C2005921).

Conflicts of Interest: The authors declare that they have no conflict of interest.

\section{References}

1. Luzio, J.P.; Pryor, P.R.; Bright, N.A. Lysosomes: Fusion and function. Nat. Rev. Mol. Cell Biol. 2007, 8, 622-632. [CrossRef] [PubMed]

2. Appelqvist, H.; Waster, P.; Kagedal, K.; Ollinger, K. The lysosome: From waste bag to potential therapeutic target. J. Mol. Cell. Biol. 2013, 5, 214-226. [CrossRef] [PubMed]

3. de Duve, C.; de Barsy, T.; Poole, B.; Trouet, A.; Tulkens, P.; Van Hoof, F. Commentary. Lysosomotropic agents. Biochem. Pharmacol. 1974, 23, 2495-2531. [CrossRef]

4. Marceau, F.; Bawolak, M.T.; Lodge, R.; Bouthillier, J.; Gagne-Henley, A.; Gaudreault, R.C.; Morissette, G. Cation trapping by cellular acidic compartments: Beyond the concept of lysosomotropic drugs. Toxicol. Appl. Pharmacol. 2012, 259, 1-12. [CrossRef] [PubMed]

5. Pisonero-Vaquero, S.; Medina, D.L. Lysosomotropic Drugs: Pharmacological Tools to Study Lysosomal Function. Curr. Drug Metab. 2017, 18, 1147-1158. [CrossRef] [PubMed]

6. Kuzu, O.F.; Toprak, M.; Noory, M.A.; Robertson, G.P. Effect of lysosomotropic molecules on cellular homeostasis. Pharmacol. Res. 2017, 117, 177-184. [CrossRef]

7. Zhang, Y.; Liao, Z.; Zhang, L.J.; Xiao, H.T. The utility of chloroquine in cancer therapy. Curr. Med. Res. Opin. 2015, 31, 1009-1013. [CrossRef]

8. Boya, P.; Gonzalez-Polo, R.A.; Poncet, D.; Andreau, K.; Vieira, H.L.; Roumier, T.; Perfettini, J.L.; Kroemer, G. Mitochondrial membrane permeabilization is a critical step of lysosome-initiated apoptosis induced by hydroxychloroquine. Oncogene 2003, 22, 3927-3936. [CrossRef]

9. Maycotte, P.; Aryal, S.; Cummings, C.T.; Thorburn, J.; Morgan, M.J.; Thorburn, A. Chloroquine sensitizes breast cancer cells to chemotherapy independent of autophagy. Autophagy 2012, 8, 200-212. [CrossRef]

10. Fitzwalter, B.E.; Towers, C.G.; Sullivan, K.D.; Andrysik, Z.; Hoh, M.; Ludwig, M.; O’Prey, J.; Ryan, K.M.; Espinosa, J.M.; Morgan, M.J.; et al. Autophagy Inhibition Mediates Apoptosis Sensitization in Cancer Therapy by Relieving FOXO3a Turnover. Dev. Cell 2018, 44, 555-565. [CrossRef]

11. Pan, H.; Wang, Z.; Jiang, L.; Sui, X.; You, L.; Shou, J.; Jing, Z.; Xie, J.; Ge, W.; Cai, X.; et al. Autophagy inhibition sensitizes hepatocellular carcinoma to the multikinase inhibitor linifanib. Sci. Rep. 2014, 4, 6683-6692. [CrossRef] [PubMed] 
12. Wang, F.; Zhang, Z.; Leung, W.T.; Chen, J.; Yi, J.; Ying, C.; Yuan, M.; Wang, M.; Zhang, N.; Qiu, X.; et al. Hydroxychloroquine reverses the drug resistance of leukemic K562/ADM cells by inhibiting autophagy. Mol. Med. Rep. 2019, 20, 3883-3892. [CrossRef] [PubMed]

13. Makowska, A.; Eble, M.; Prescher, K.; Hoss, M.; Kontny, U. Chloroquine Sensitizes Nasopharyngeal Carcinoma Cells but Not Nasoepithelial Cells to Irradiation by Blocking Autophagy. PLoS ONE 2016, 11, e0166766. [CrossRef] [PubMed]

14. Cascioferro, S.; Parrino, B.; Spano, V.; Carbone, A.; Montalbano, A.; Barraja, P.; Diana, P.; Cirrincione, G. 1,3,5-Triazines: A promising scaffold for anticancer drugs development. Eur. J. Med. Chem. 2017, 142, 523-549. [CrossRef]

15. Kumar, G.J.; Kumar, S.N.; Thummuri, D.; Adari, L.B.S.; Naidu, V.; Srinivas, K.; Rao, V.J. Synthesis and characterization of new s-triazine bearing benzimidazole and benzothiazole derivatives as anticancer agents. Med. Chem. Res. 2015, 24, 3991-4001. [CrossRef]

16. Guntuku, L.; Gangasani, J.K.; Thummuri, D.; Borkar, R.M.; Manavathi, B.; Ragampeta, S.; Vaidya, J.R.; Sistla, R.; Vegi, N.G. IITZ-01, a novel potent lysosomotropic autophagy inhibitor, has single-agent antitumor efficacy in triple-negative breast cancer in vitro and in vivo. Oncogene 2019, 38, 581-595. [CrossRef]

17. Marsters, S.A.; Pitti, R.A.; Sheridan, J.P.; Ashkenazi, A. Control of apoptosis signaling by Apo2 ligand. Recent Prog. Horm. Res. 1999, 54, 225-234.

18. Kretz, A.-L.; Trauzold, A.; Hillenbrand, A.; Knippschild, U.; Henne-Bruns, D.; von Karstedt, S.; Lemke, J. Trailblazing strategies for cancer treatment. Cancers 2019, 11, 456. [CrossRef]

19. Trivedi, R.; Mishra, D.P. Trailing TRAIL Resistance: Novel Targets for TRAIL Sensitization in Cancer Cells. Front. Oncol. 2015, 5, 69-88. [CrossRef]

20. de Miguel, D.; Lemke, J.; Anel, A.; Walczak, H.; Martinez-Lostao, L. Onto better TRAILs for cancer treatment. Cell Death Differ. 2016, 23, 733-747. [CrossRef]

21. Walczak, H.; Degli-Esposti, M.A.; Johnson, R.S.; Smolak, P.J.; Waugh, J.Y.; Boiani, N.; Timour, M.S.; Gerhart, M.J.; Schooley, K.A.; Smith, C.A. TRAIL-R2: A novel apoptosis-mediating receptor for TRAIL. EMBO J. 1997, 16, 5386-5397. [CrossRef] [PubMed]

22. Jung, Y.-H.; Heo, J.; Lee, Y.J.; Kwon, T.K.; Kim, Y.-H. Quercetin enhances TRAIL-induced apoptosis in prostate cancer cells via increased protein stability of death receptor 5. Life Sci. 2010, 86, 351-357. [CrossRef] [PubMed]

23. Park, E.J.; Min, K.-j.; Choi, K.S.; Kubatka, P.; Kruzliak, P.; Kim, D.E.; Kwon, T.K. Chloroquine enhances TRAIL-mediated apoptosis through up-regulation of DR5 by stabilization of mRNA and protein in cancer cells. Sci. Rep. 2016, 6, 1-11. [CrossRef] [PubMed]

24. Song, J.J.; Szczepanski, M.J.; Kim, S.Y.; Kim, J.-H.; An, J.Y.; Kwon, Y.T.; Alcala Jr, M.A.; Bartlett, D.L.; Lee, Y.J. c-Cbl-mediated degradation of TRAIL receptors is responsible for the development of the early phase of TRAIL resistance. Cell. Signal. 2010, 22, 553-563. [CrossRef] [PubMed]

25. Qu, J.; Zhao, M.; Teng, Y.; Zhang, Y.; Hou, K.; Jiang, Y.; Yang, X.; Shang, H.; Qu, X.; Liu, Y. Interferon-alpha sensitizes human gastric cancer cells to TRAIL-induced apoptosis via activation of the c-CBL-dependent MAPK/ERK pathway. Cancer Biol. Ther. 2011, 12, 494-502. [CrossRef]

26. Duan, L.; Miura, Y.; Dimri, M.; Majumder, B.; Dodge, I.L.; Reddi, A.L.; Ghosh, A.; Fernandes, N.; Zhou, P.; Mullane-Robinson, K.; et al. Cbl-mediated ubiquitinylation is required for lysosomal sorting of epidermal growth factor receptor but is dispensable for endocytosis. J. Biol. Chem. 2003, 278, 28950-28960. [CrossRef]

27. Haglund, K.; Shimokawa, N.; Szymkiewicz, I.; Dikic, I. Cbl-directed monoubiquitination of CIN85 is involved in regulation of ligand-induced degradation of EGF receptors. Proc. Natl. Acad. Sci. USA 2002, 99, 12191-12196. [CrossRef]

28. Goldman, M.J.; Craft, B.; Hastie, M.; Repecka, K.; McDade, F.; Kamath, A.; Banerjee, A.; Luo, Y.; Rogers, D.; Brooks, A.N.; et al. Visualizing and interpreting cancer genomics data via the Xena platform. Nat. Biotechnol. 2020, 38, 675-678. [CrossRef]

29. Karpel-Massler, G.; Banu, M.A.; Shu, C.; Halatsch, M.-E.; Westhoff, M.-A.; Bruce, J.N.; Canoll, P.; Siegelin, M.D. Inhibition of deubiquitinases primes glioblastoma cells to apoptosis in vitro and in vivo. Oncotarget 2016, 7, 12791-12805. [CrossRef]

30. Jehn, B.M.; Dittert, I.; Beyer, S.; von der Mark, K.; Bielke, W. c-Cbl binding and ubiquitin-dependent lysosomal degradation of membrane-associated Notch1. J. Biol. Chem. 2002, 277, 8033-8040. [CrossRef] 
31. Ye, S.; Cihil, K.; Stolz, D.B.; Pilewski, J.M.; Stanton, B.A.; Swiatecka-Urban, A. c-Cbl facilitates endocytosis and lysosomal degradation of cystic fibrosis transmembrane conductance regulator in human airway epithelial cells. J. Biol. Chem. 2010, 285, 27008-27018. [CrossRef] [PubMed]

32. Naramura, M.; Jang, I.K.; Kole, H.; Huang, F.; Haines, D.; Gu, H. c-Cbl and Cbl-b regulate T cell responsiveness by promoting ligand-induced TCR down-modulation. Nat. Immunol. 2002, 3, 1192-1199. [CrossRef] [PubMed]

33. Fasen, K.; Cerretti, D.P.; Huynh-Do, U. Ligand binding induces Cbl-dependent EphB1 receptor degradation through the lysosomal pathway. Traffic 2008, 9, 251-266. [CrossRef] [PubMed]

34. Min, K.J.; Woo, S.M.; Shahriyar, S.A.; Kwon, T.K. Elucidation for modulation of death receptor (DR) 5 to strengthen apoptotic signals in cancer cells. Arch. Pharm. Res. 2019, 42, 88-100. [CrossRef] [PubMed]

35. Wu, Y.; Kimura, Y.; Okamoto, T.; Matsuhisa, K.; Asada, R.; Saito, A.; Sakaue, F.; Imaizumi, K.; Kaneko, M. Inflammatory bowel disease-associated ubiquitin ligase RNF183 promotes lysosomal degradation of DR5 and TRAIL-induced caspase activation. Sci. Rep. 2019, 9, 20301-20312. [CrossRef]

36. Liu, T.; Brouha, B.; Grossman, D. Rapid induction of mitochondrial events and caspase-independent apoptosis in Survivin-targeted melanoma cells. Oncogene 2004, 23, 39-48. [CrossRef]

37. Altieri, D.C. Survivin and IAP proteins in cell-death mechanisms. Biochem. J. 2010, 430, 199-205. [CrossRef]

38. Zhao, J.; Tenev, T.; Martins, L.M.; Downward, J.; Lemoine, N.R. The ubiquitin-proteasome pathway regulates survivin degradation in a cell cycle-dependent manner. J. Cell Sci. 2000, 113, 4363-4371.

39. Arora, V.; Cheung, H.H.; Plenchette, S.; Micali, O.C.; Liston, P.; Korneluk, R.G. Degradation of survivin by the X-linked inhibitor of apoptosis (XIAP)-XAF1 complex. J. Biol. Chem. 2007, 282, 26202-26209. [CrossRef]

40. Reyes-Turcu, F.E.; Ventii, K.H.; Wilkinson, K.D. Regulation and cellular roles of ubiquitin-specific deubiquitinating enzymes. Annu. Rev. Biochem. 2009, 78, 363-397. [CrossRef]

41. Chen, H.; Yang, F.; Li, X.; Gong, Z.-J.; Wang, L.-W. Long noncoding RNA LNC473 inhibits the ubiquitination of survivin via association with USP9X and enhances cell proliferation and invasion in hepatocellular carcinoma cells. Biochem. Biophys. Res. Commun. 2018, 499, 702-710. [CrossRef] [PubMed]

42. Woo, S.M.; Seo, S.U.; Kubatka, P.; Min, K.J.; Kwon, T.K. Honokiol Enhances TRAIL-Mediated Apoptosis through STAMBPL1-Induced Survivin and c-FLIP Degradation. Biomolecules 2019, 9, 838. [CrossRef] [PubMed]

43. Joseph, L.; Srinivasan, K.K. Triacontanoic ester of 5"-hydroxyjustisolin: Tumour suppressive role in cervical cancer via Bcl-2, BAX and caspase-3 mediated signalling. Toxicol. Rep. 2019, 6, 1198-1205. [CrossRef] [PubMed]

44. Seo, S.U.; Min, K.J.; Woo, S.M.; Kwon, T.K. Z-FL-COCHO, a cathepsin S inhibitor, enhances oxaliplatin-mediated apoptosis through the induction of endoplasmic reticulum stress. Exp. Mol. Med. 2018, 50, 107-117. [CrossRef]

45. Seo, S.U.; Woo, S.M.; Kim, M.W.; Lee, H.S.; Kim, S.H.; Kang, S.C.; Lee, E.W.; Min, K.J.; Kwon, T.K. Cathepsin $\mathrm{K}$ inhibition-induced mitochondrial ROS enhances sensitivity of cancer cells to anti-cancer drugs through USP27x-mediated Bim protein stabilization. Redox Biol. 2020, 30, 101422-101434. [CrossRef] [PubMed]

46. Woo, S.M.; Seo, S.U.; Min, K.-J.; Kwon, T.K. BIX-01294 sensitizes renal cancer Caki cells to TRAIL-induced apoptosis through downregulation of survivin expression and upregulation of DR5 expression. Cell Death Discov. 2018, 4, 1-11. [CrossRef]

47. Seo, B.R.; Min, K.-j.; Woo, S.M.; Choe, M.; Choi, K.S.; Lee, Y.-K.; Yoon, G.; Kwon, T.K. Inhibition of cathepsin S induces mitochondrial ROS that sensitizes TRAIL-mediated apoptosis through p53-mediated downregulation of Bcl-2 and c-FLIP. Antioxid. Redox Signal. 2017, 27, 215-233. [CrossRef]

(C) 2020 by the authors. Licensee MDPI, Basel, Switzerland. This article is an open access article distributed under the terms and conditions of the Creative Commons Attribution (CC BY) license (http://creativecommons.org/licenses/by/4.0/). 